Malaysian Journal of Social Sciences and Humanities (MJSSH)

Volume 4, Issue 7, November 2019

e-ISSN : 2504-8562

Journal home page:

www.msocialsciences.com

\title{
Kepimpinan Instructional Penyelia Operasi Pendidikan Awal Kanak-kanak dan Hubungnya dengan Kepuasan Kerja Pemaju Masyarakat TABIKA atau TASKA KEMAS
}

\author{
Mary Jipin1, Abdul Said Ambotang1 \\ 1Fakulti Psikologi dan Pendidikan, Universiti Malaysia Sabah (UMS) \\ Correspondence: Mary Jipin (mjipin48@gmail.com)
}

\begin{abstract}
Abstrak
Kertas konsep ini bertujuan untuk membincangkan mengenai kepimpinan instruktional dalam kalangan Penyelia Pendidikan awal kanak-kanak dan kepuasan kerja guru Tabika/Taska KEMAS. Dalam era globlalisasi yang pesat dengan pembangunan teknologi alam maya, pemimpin dan peneraju pendidikan awal kanak-kanak perlu mempunyai kompetensi seiring dengan tranformasi pendidikan yang telah dirancang. Kepimpinan instruktional dalam kalangan Penyelia Operasi Pendidikan Awal Kanak-kanak Jabatan Kemajuan Masyarakat KEMAS perlu di implementasikan untuk mencapai tahap kepimpinan optimum yang selaras dengan Standard Kualiti Prasekolah Kebangsaan. Kajian tinjauan ini dilaksanakan bagi tujuan untuk mengenalpasti tahap kepimpinan instruksional Penyelia Operasi Pendidikan Awal Kanak-kanak dan hubunganya dengan kepuasan kerja, Pemaju Masyarakat Tabika/Taska (guru) KEMAS. Seramai 24 orang Penyelia Operasi Pendidikan awal Kanak-kanak dari 24 Parlimen dan 240 Pemaju Masyarakat Tabika/Taska KEMAS di Sabah akan dipilih dalam kajian ini. Seterusnya kajian ini memberi implikasi bahawa pengaruh tahap kepimpinan Penyelia Operasi Pendidikan Awal Kanak-Kanak dan kepuasan kerja Pemaju Masyarakat Tabika/Taska amat penting untuk memastikan halatuju pendidikan awal kanak-kanak di Jabatan KEMAS.
\end{abstract}

Kata kunci: pendidikan awal kanak-kanak, kepimpinan, intruksional, penyelia operasi pendidikan awal kanak-kanak, kepuasan kerja

\section{Instructional Leadership Among Early Childhood Educational Supervisors and It's Correlation Towards Teacher's Job Satisfaction}

\begin{abstract}
This concept paper is intended to discuss instructional leadership among early childhood Education Supervisors and KEMAS kindergarten and nursery teachers' job satisfaction. In an era of rapid globalization with the development of digital technologies, early childhood leaders need to be competent in line with the planned educational transformation. Instructional leadership among the Early Childhood Education Operations Supervisors of the KEMAS Community Development Department needs to be implemented to achieve optimal leadership levels in line with the National Preschool Quality Standards. This research study was conducted to identify the instructional leadership level of Early Childhood Education Operations Supervisors and their relationship with job satisfaction, KEMAS kindergarten and nursery teachers. A total of 24 Early Childhood Education Operations Supervisors from 24 Parliaments and 240 KEMAS kindergarten and nursery teachers in Sabah will be selected in this study. Furthermore, this study suggests that the influential of the leadership level of
\end{abstract}


Early Childhood Education Operations Supervisors and the work satisfaction of the kindergarten and nursery teachers is crucial in ensuring the early childhood education goals of the KEMAS Department.

Keywords: early childhood, leadership, instructional, early childhood supervisor

\section{Pengenalan}

Pendidikan awal kanak-kanak merupakan satu agenda penting dalam Pelan Pembangunan Pendidikan Malaysia PPPM 2013-2025. Sesuai dengan aspirasi tersebut Kementerian Pembangunan Luar Bandar melalui Jabatan Kemajuan Masyarakat mengwujudkan perkhidmatan prasekolah TABIKA/TASKA KEMAS khusus untuk kanak-kanak yang berada di kawasan Luar Bandar dan pedalaman. Perkhidmatan Pendidikan Awal Kanak-kanak KEMAS terbahagi kepada dua bahagian iaitu Tabika dan Taska. Taska Kemas menawarkan perkhidmatan penjagaan dan pendidikan kepada kanak-kanak yang berumur dua hingga empat tahun manakala, Tabika Kemas bertujuan untuk membimbing dan mendidik kanak-kanak berusia empat hingga enam tahun. Penubuhan pendidikan awal kanak-kanak dibawah Jabatan Kemajuan Masyarakat bermula dari inspirasi Kementerian Pembangunan Luar Bandar memajukan masyarakat luar bandar.

\section{Jabatan Kemajuan Masyarakat KEMAS}

Jabatan Kemajuan Masyarakat dikenali dengan nama (KEMAS) yang juga merupakan singkatan daripada 'Kemajuan Masyarakat'. Pada asalnya KEMAS dikenali dengan nama Bahagian Pelajaran Dewasa. Bahagian Pelajaran Dewasa ini ditubuhkan secara rasmi oleh YAB Tun Abdul Razak Bin Hussien pada tahun 1961. Penubuhan Bahagian Pelajaran Dewasa pada waktu tersebut dilakukan setelah negara mencapai Kemerdekaan pada tahun 1957 berikutan dari satu bancian yang telah dilakukan dan mendapati seramai 1,868,948 orang dewasa dan 2,379,213 orang kanak-kanak yang berumur antara 10 hingga 14 tahun tidak tahu dan tidak boleh membaca dan menulis. Pekara ini dilihat menjadi halangan utama untuk kerajaan melaksanakan agenda pembangunan negara.

Sepanjang tahun 2001 hingga 2019, fungsi dan peranan KEMAS adalah meliputi tiga daripada lima teras Misi Nasional iaitu meningkatkan keupayaan pengetahuan dan inovasi negara serta memupuk minda kelas pertama dan menangani masalah ketidaksamaan sosio-ekonomi yang berterusan secara membina dan produktif di bawah Gerakan Daya Wawasan; Pendidikan Literasi Komputer, Pendidikan Kesejahteraan Keluarga, Pendidikan Kemahiran, Pendidikan Literasi Fungsian dan Pusat Sumber, konsep pendidikan berterusan selaras dengan pembangunan modal insan di bawah Bahagian Bina Insan; Program Pendidikan Awal Kanak-Kanak (Tabika dan Taska) serta Program Makanan Tambahan untuk kanak-kanak.

Pelan harapan Pembangunan Luar Bandar 2018 - 2023 meletakan Pendidikan Awal kanak-kanak di bawah KEMAS teras 4 modal insan dengan meletakan strategi untuk memperbanyakan lagi Pusat Jagaan Kanak-Kanak dan Pra-Sekolah Kemas. Visi bahagian Pendidikan Awal Kanak-kanak adalah untuk memberikan Pendidikan berkualiti, seimbang dan holistik kearah kesejahteraan kanak-kanak. Misi bahagian ini pula adalah meningkatkan pengurusan pendidikan awal kanak-kanak yang efektif dan efisyen dalam merealisasikan harapan negara. Sehingga februari 2019, bahagian ini berjaya merekodkan 188,940 kanak-kanak dua hingga enam tahun, 214 orang Penyelia Operasi Pendidikan Awal Kanak-kanak, Pemaju Masyarakat Tabika/Taska seramai 11705 orang dan 77 buah Tabika Transit Kemas.

\section{Kepimpinan Instruksional}

Menurut Azman (2010) kepimpinan dan pekerja merupakan aset penting bagi sesebuah organisasi. Menurut beliau juga, gaya kepimpinan motivasi, komitment dan kepuasan kerja di kalangan pekerja 
mempunyai kaitan di antara satu sama lain dan akan memberi kesan kepada organisasi. Sisman (2016), merujuk kepimpinan pengajaran sebagi kuasa dan tingkahlaku yang digunakan oleh pemimpin sekolah, guru dan penyelia sekolah dalam mempengaruhi individu dan sekolah. Pekara utama yang membezakan kepimpinan instruksional dengan gaya kepimpinan lain ialah kepimpinan instruksional lebih menumpuhkan kepada proses pengajaran dan pembelajaran di sekolah. Menurut beliau terdapat lima tingkahlaku kepimpinan instruksional yang harus diamalkan oleh pemimpin sekolah iaitu, (1) mengenalpasti dan berkongsi objektif sekolah, (2) mengurus kurikulum dan proses instruksional, (3) menilai proses pengajaran dan pencapaian akademik pelajar, (4) menyokong guru sambil meningkatkan kualiti mereka dan (5) mencipta persekitaran pembelajaran dan iklim sekolah yang positif.

Hallinger (2012) menyatakan bahawa kepimpinan instruksional adalah usaha yang dilakukan oleh pemimpin sekolah untuk memperbaiki proses pengajaran dan pembelajaran yang melibatkan guru, ibubapa, pelajar dan gabungan pengurusan, organisasi, kemudahan dan budaya sekolah. Pemimpin sekolah perlu memastikan setiap individu di sekolah bekerjasama dan membantu satu sama lain dalam melaksanakan program pendidikan terbaik. Menurut beliau konsep kepimpinan instruksional telah dikaji secara meluas pada tahun 1980an dan 1990an. Pelbagai kajian tentang sekolah berkesan, pelaksanaan perubahan, dan penambahbaikan sekolah yang dilaksanakan di pelbagai negara telah menjadi asas kepada perkembangan kepimpinan instruksional.

Kajian Dolly Ratcha dan Mohd Yusoff, (2017) mengenai hubungan kepimpinan guru besar dengan kepuasan kerja guru di sekolah rendah daerah Julau menunjukkan bahawa tahap amalan kepimpinan instruksional bagi ketiga-tiga dimensi dan kepuasan kerja guru berada pada tahap yang sangat tinggi. Guru besar daerah Julau berjaya mengamalkan amalan kepimpnan instruksional dengan baik dan berkesan. Tahap kepuasan kerja dalam Daerah Jualau yang tinggi membuktikan bahawa guru sangat seronok di sekolah yang mana guru besarnya mengamalkan kepimpinan instruksional seterusnya dapat meningkatkan prestasi akademik sekolah. Kajian Johan dan Jamalul lail, (2017) juga mendapati bahawa terdapat hubungan positif antara kepimpinan instruksional guru besar dengan kepuasan kerka guru. Dapatan ini menunjukkan bahawa kepimpinan instruksional sangat penting dalam membentuk sebuah sekolah yang cemerlang.

Kajian Dayang Hayati dan Mohd Yusoff,(2017) mendapati kepimpinan instruksional guru besar bukanlah penyumbang utama kepada kepuasan kerja, namun guru dan guru besar serta pentadbir sekolah perlu mengambil perhatian terhadap dimensi-dimensi kepimpinan instruksional untuk kemajuan sekolah. Mohd,mohd Yusoff, Azizo dan Syukri, (2017) mendapati kajian mereka tentan kepimpinan instruksional guru besar dengan kepuasan kerja guru di Bachok mendapati terdapat hubungan positif antara kepimpinan pengajaran guru besar dengan komitment dan kepuasan guru. Sekiranya guru besar mengamalkan kepimpinan instruksional guru-guru akan lebih komited dan berpuashati seterusnya dapat mendidik pelajar dengan lebih baik.

\section{Kepuasan Kerja}

Kepuasan kerja pada dasarnya merupakan kehendak naluri yang bersifat individual bagi setiap individu yang berkerja. Seseorang individu akan berpuashati dalam kerja sekiranya nilai-nilai peribadi dan jangkaan terhadap kerja selari dengan ciri-ciri kerja (Locke 1976). Kepuasan guru sentias dikaji kerana ianya amat berpengaruh dalam pembentukan tingkahlaku dan prestasi guru. Guru yang tidak berpuashati dengan kerja mereka mempaparkan komitment yang lebih rendah dan berisiko tinggi untuk meninggalkan profesion keguruan (Ingersoll, 2001). Dinham dan Scott (2000) menyatakan seseorang individu dapat berpuas hati dan meningkatkan prestasinya jika diberi tugas yang mencabar.

Teori Hierarki Keperluan Maslow diperkenalkan oleh Abraham H. Maslow pada tahun (1967). Merujuk pada teori ini, setiap individu mempunyai keperluan mengikut keutamaan untuk mencapai kepuasan diri. Maslow telah mengelaskan keperluan manusia kepada lima peringkat keperluan mengikut hierarki iaitu fsiologi, keselamatan, sosial, penghargaan diri dan pencapaian kesempurnaan 
diri. Kajian ini hanya menggunakan Teori Keperluan Maslow kerana kesesuaian teori dengan konsep kepuasan kerja yang ingin dikaji.

\section{Kajian - kajian Lepas kepimpinan Instruksional dan kepuasan Kerja Guru}

Jamelaa (2012), dalam kajiannya yang meninjau amalan kepimpinan instruksional pengetua di enam buah sekolah menengah di Negeri Pahang yang berasaskan kepada empat dimensi kepimpinan instruksional mendapati bahawa amalan instruksional berlaku di sekolah tersebut. Dapatan kajain yang dijalankan menunjukkan bahawa keenam-enam buah sekolah di Negeri Pahang sebagai sampel mengamalkan kepimpinan instruksional untuk mentadbir sekolah. Kajian lain seperti Munaim dan Norlela (2015) menunjukkan amalan mendefinisikan dan menyebarkan maklumat sekolah berada pada tahap sangat tinggi dan dimensi mematuhi dan memberi maklumbalas kepada guru di sekolah. Dapatan kajian juga membuktikan bahawa guru besar di sekolah kurang murid melakukan amalan kepimpinan instruksional pada tahap tinggi.

Diana dan Jamalul (2017), dalam kajian mereka terhadap amalan gaya kepimpinan instruksional pengetua di sekolah menengah swasta daerah Miri dan hubunganya dengan kepuasan kerja guru mendapati pengetua menentukan matlamat berdasarkan data prestasi pelajar adalah pada tahap min yang paling tinggi. Jen Leong dan Azlin (2017), dalam kajian mereka teerhadap kepuasan kerja dalam kalangan guru sekolah rendah di Daerah Meraong, Sarawak mendapati guru-guru sekolah rendah jenis kebangsaan cina SKM Gred B dalam daerah Meradong mempunyai tahap kepuasan kerja yang tinggi. Kajian mereka juga mendapati jantina dan kelulusan akademik tertinggi tidak mempengaruhi kepuasan kerja guru. Namun tempoh pengalaman mengajar seseorang guru didapati mempengaruhi kepuasan kerja mereka. Selain pengetua dan guru, kepimpinan instruksional perlu melibatkan keupayaan untuk memasukkan semua pihak berkepentingan dalam masyarakat agar mewujudkan persekitaran pembelajaran agar komuniti mengetahui kesan kepelbagaian atas hasil pembelajaran dan aktif menyumbang kepada kesedaran, kecekapan dan ekuiti budaya dalam semua bidang pembelajaran Chen, (2017).

\section{Metod Kajian}

Kajian ini menggunakan pendekatan kuantitatif yang akan dipersembahkan dalam bentuk deskritif dan empirikal. Populasi kajian terdiri daripada Penyelia Operasi Pendidikan Awal Kanak-Kanak sebagai pemimpin dan Pemaju Masyarakat sebagai Guru. Sampel akan diambil dari 24 orang Penyelia Operasi Pendidikan Awal Kanak-Kanak dan 240 orang guru Tabika/Taska Kemas. Persampelan tujuan (purposive sampling atau judgment sampling) adalah prosedur persampelan terhadap sekumpulan sasaran kajian (responden) yang mempunyai ciri-ciri tertenu sahaja (Fuad Mohamed, 2017). Borang soal selidik yang akan digunakan sebagai instrumen kajian terdiri dari dua set iaitu Set A untuk Penyelia Operasi Pendidikan Awal Kanak-kanak manakala set B untuk guru Tabika/Taska Kemas. Data yang diperolehi akan dianalisis menggunakan statistik deskritif dan inferen menggunakan Statistik Package for Sosial Science (SPSS).

\section{Rumusan}

Organisasi dan kepimpinan umpama tiang tonggak yang sangat penting dalam memastikan kejayaan sesebuah negara. Penyelia perlu melakukan kerja penyeliaan dan pengurusan sebaik mungkin untuk mengimbangi respon dari subordinat bawahan mereka. Gaya atau aura kepimpinan yang diamalkan oleh seorang penyelia seharusnya dapat mendorong kepada kejayaan bahagian pendidikan awal kanakkanak. Kesimpulanya sebagai peneraju utama pendidikan awal kanak-kanak di Malaysia KEMAS perlu memastikan pemimpin yang menyelia golongan guru-guru KEMAS adalah pemimpin yang dapat membentuk dan menyediakan iklim kerja yang mampu meningkatkan prestasi kerja setiap guru Tabika/Taska KEMAS. 


\section{Rujukan}

Azizi Yahya, Peter Voo, Ismail Maakip dan Mohd Dahlan A. Malek, (2017). Kaedah Penyelidikan dalam pendidikan. Tanjung Malim, Perak: Penerbit Universiti Pendidikan Sultan Idris.

Azman, I. \& Nurul Inani, I. (2010). Motivasi latihan sebagai pembolehubah penghubung antara program latihan dan keberkesanan latihan. Jurnal Kemanusiaan Bil 6.

Berawi, Fuad Muhamed, (2017). Metodologi Penyelidikan, Panduan Menulis Tesis. Sintok Kedah: UUM Press.

Diana Lu Li Li, Jamalul Lail Abdul Wahab. (2017). Amalan Gaya Kepimpinan Instruksional Pengetua di Sekolah Menengah Swasta Daerah Miri dan hubunganya dengan kepuasan kerja guru. Seminar Penyelidikan Pendidikan 2017, P-542-552.

Danielle Fong, Mohd Khairuddin.(2017). Analisis Perbandingan Kepimpinan Instruksional Pengetua Dan Kepuasan Kerja Guru. Jurnal of Education, Psychology and Counseling 2(5),318-339.

Dayang Hayanti, Mohamed Yusoff, (2017). Kepimpinan Instruksional Guru Besar dan Kepuasan Kerja Guru. Seminar Penyelidikan Pendidikan 2017, P-514-525.

Dolly Ratcha , Mohamed Yusoff, (2017). Amalan Kepimpinan Guru dan Hubunganya Dengan Kepuasan Kerja Guru Sekolah Rendah di Daerah Julau. Seminar Penyelidikan Pendidikan 2017,P-553-568.

Hallinger P, Murphy JF.(1987). Menilai dan membangun prinsipal kepimpinan instruksional. Educational Leadership. 45(1): 54-62.

Hallinger P. (2003). Leading Educational Change: Reflections On Practise Of Instructional And Transformational Leadership. Cambridge Journal of Educational, 13(3), 219-356.

Hallinger P. Kajian semula dua dekad mengenai pengetua dengan menggunakan Penilaian Pengurusan Utama Skala. Dalam Kertas dibentangkan pada mesyuarat tahunan Amerika Persatuan Penyelidikan, Seattle, Washington. 2000.

Hallinger P.2011. Kajian tiga dekad kajian doktoral menggunakan Skala Penarafan Penilaian Pengajaran Utama: Kanta pada Kemajuan metodologi dalam Pengajaran Utama: Kanta pada kemajuan metodologi dalam kepimpinan pendidikan. Educ Adm Q. 2011; 47 (2); 271-306.

Hallinger, P. (2012). A Data-Driven Approach To Assess And Develop Instructional Leadership with the PIMRS. In Shen, J., Tools for Improvings' work (pp.4769). New York : Peter Lang Publishing.

Ingersoll, R. (2001). Teacher turnover and teacher shortage. American Educational Research Journal, $38(3), 499-534$.

Jamelaa, B. A. 2012. Amalan Kepimpinan Instruksional dan Sikap Terhadap Perubahan Dalam Kalangan Pengetua Sekolah Menengah di Negeri Pahang. Thesis Dr. Fal. Universiti Kebangsaan Malaysia.

James AJE, Balasandran R. Kepimpinan Instruksional:Satu Panduan Praktikal. Ed ed. Kuala Lumpur:PTS Akademia; 2013.

Johan, Jamalul, (2017). Amalan Kepimpinan Instruksional Guru Besar dan Hubunganya Dengan Kepuasan Kerja Guru Di Daerah Asajaya. Seminar Penyelidikan Pendidikan 2017 : P- 617-630.

Lay Yoon Fah, Khoo Chwee Hoon, (2014). Pengenalan kepada Pendekatan Kuantitatif dalam Penyelidikan Pendidikan. Kota Kinabalu, Sabah: Penerbit Universiti Malaysia Sabah.

Laporan Tahunan Jabatan Kemajuan Masyarakat 2017.

Locke, E. A. 1976. Handbook of Industrial and organizational Psychology. Randy McNally College Publishing Company. 1297-1350.

Nur Faezah, Dg Norizah, (2018). Kepimpinan Pengajaran, Sekolah Berkesan dan Peradaban Organisasi di Pedalaman Sarawak. Malaysian Journal of Social Sciences and Humaities (MJ$\mathrm{SSH}), 3,2,127-136$.

Normiati, Abdul Said, (2019). Pengaruh Pengajaran Guru Terhadap Kualiti Pengajaran Guru. Malaysian Journal of Social Sciences and Humaities (MJ-SSH), 4, 2, 30-42.

Sisman M. Faktor yang berkaitan dengan persepsi kepimpinan pengajaran dan kesan kepimpinan instruksional ke atas pembolehubah organisasi: A meta-analisis. Educ Sci Theory Pract. 2016; 16 (5): 1761-87.

Wong Jen Leong, Azlin Noraini Mansor.(2017). Kepuasan Kerja dalam kalangan guru sekolah rendah di Daerah Meradong, Sarawak. Seminar Penyelidikan Pendidikan 2017, 848-859. 